Investigaciones Fenomenológicas, n. 10, 2013, 33-51.

e-ISSN: $1885-1088$

\title{
JUICIO MORAL Y CORAZÓN: COORDENADAS \\ PARA UN EQUILIBRIO A PARTIR DEL ROSMIANISMO
}

\author{
MORAl Judgment AND HeART: \\ COORDINATES FOR A BALANCE FROM ROSMINI
}

\begin{abstract}
Resumen: En este trabajo, que en su origen fue una conferencia dictada en la Facultad de Filosofía de la Universidad Michoacana de San Nicolás de Hidalgo el 21 de agosto del 2012, el autor tiene la intención de examinar, a partir de la filosofía de Antonio Rosmini, la relación entre el juicio práctico y el corazón o sentimiento, a la luz de ciertas consideraciones morales. Luego de algunas consideraciones sobre el mismo asunto a partir de las reflexiones psicoteológico-morales del juicio moral que Boies, el autor dialoga a partir de la postura rosminiana con la fenomenología ética del corazón de Roberta de Monticelli.
\end{abstract}

Palabras clave: Filosofía moral rosminiana, juicio moral, esencial de la moralidad, corazón y fenomenología de Roberta de Monticelli.

\begin{abstract}
I In this work, which was originally a lecture at the Faculty of Philosophy at the Universidad Michoacana de San Nicolás de Hidalgo on August 21, 2012, the author intends to examine, from the point of view of the philosophy of Antonio Rosmini, the relationship between practical judgment and heart or feeling, in the light of moral considerations. After some remarks on the same subject from the psychotheological reflections about the moral judgment according to Boies, the author discuss with the ethical phenomenology of Roberta de Monticelli.
\end{abstract}

Key Words: Rosminian moral philosophy, moral judgment, the essence of morality, heart and phenomenology of Roberta de Monticelli.

\section{INTRODUCCIÓN}

El tema del sentimiento, la afección o emoción (como bien se sabe, estos conceptos guardan diferencias entre sí, pero en este momento los tomamos de manera general), englobado a veces bajo el término de "corazón" en relación con el juicio moral, ha tenido una impresionante recepción y desarrollo en la 
filosofía contemporánea, especialmente en la fenomenología. Varios son los filósofos que se han volcado a este asunto que, per se, reclama toda la atención, ya que se refiere de manera directa a nuestro modo de relacionarnos con los objetos y, por supuesto, con la dimensión de la vida humana que solemos llamar "moral". Aunque el tema de la afección y su estrecho vínculo con el juicio moral no ha estado del todo ausente en la historia de la filosofía, parece que es en la Modernidad cuando adquiere un resplandor especial, el cual podemos ubicarlo en la filosofía inglesa moderna. David Hume, como en muchos otros casos, se vuelve paradigma imprescindible para esta cuestión, por lo que deberemos referirnos a él, aunque sea para apreciar algunas tesis de lo que más adelante en la historia de la filosofía se llamará "emotivismo", con el fin de no caer en ciertos escollos que, en vez de encontrar un equilibrio, parece llevarnos a una suerte de irracionalismo moral. Por otra parte, en Kant parece hallarse un acento especial no a la emoción o al sentimiento moral, como lo hacen los ingleses, sino al imperativo categórico de la razón práctica (aunque en honor a la verdad, también en la filosofía moral del prusiano está presente la afección, pero desde un punto de vista secundario $)^{1}$. Mucho se siguió la filosofía kantiana hasta muy temprano el siglo $\mathrm{XX}$, aunque poco se le ha sostenido luego de los años treinta del siglo pasado, siendo la última etapa importante de tal corriente de pensamiento lo que se conoce como "neokantismo", que adquiere distintos matices $^{2}$. Por su parte, y justamente en la primera mitad del siglo XX, la filosofía analítica, muy volcada al análisis del lenguaje, ha redescubierto que los enunciados morales parecen implicar siempre emociones $y$, además, que se trata de enunciados que buscan universalizar en cierto modo lo que se afirma en ellos.

Así, encontramos que en la filosofía de inspiración empirista el tema de la emoción se encuentra fuertemente presente gracias a la obra de Hume; en Kant encontramos más bien un apelo a la razón práctica como legisladora que pretende la universalidad de la máxima erigida como ley moral; y en la filosofía analítica hallamos que los enunciados morales implican emociones con pretensiones universales.

${ }^{1}$ Cf. Charpenel, Eduardo, "Los sentimientos y el deber en la filosofía práctica de Kant", en Open Insight, III/2, (2011), pp. 5-29.

${ }^{2}$ Aunque resulta muy común encontrar citado a Kant en relación con la dignidad de la persona humana, que él encuentra en la autonomía. 
Tal parece que algunos filósofos más cercanos a nosotros en el tiempo buscan rescatar, de alguna manera, ambas vertientes; es decir, tanto la parte emotiva como la racional en el campo de la filosofía moral. Pero las preguntas no dejan de sucederse unas a otras, como ocurre con la siguiente: ¿cuál de los dos ámbitos juega el papel primordial, si es que acaso uno de ellos lo desempeña? Nos parece que una distinción a la que poco se recurre, y que sería del todo provechosa para la filosofía moral, es la que se da entre el principium essendi y el principium cognoscendi de la esencia de la moralidad, que es la exigencia moral. No distinguir entre ambos principios, que ya la escolástica destacaba a su tiempo y que también en algunos filósofos modernos tiene sus cultivadores, puede acarrear o implicar ciertas confusiones que entorpecen el discurso ético. Para decirlo con brevedad, como ya sus nombres revelan de qué se trata, el principium cognoscendi ha de soportarse en el principium essendi, pues el ser tiene primacía sobre el conocer, dado que todo lo que se conoce presupone el ser y no viceversa ${ }^{3}$. Con estas coordenadas, en este trabajo tenemos la intención de repasar y revisar algunos argumentos de interés de lo que ha venido a llamarse el papel del corazón o sentimiento o emoción en el juicio moral ${ }^{4}$.

\section{EL EMOTIVISMO Y LA ÉTICA}

El emotivismo está asociado al empirismo y al nominalismo, cuyo máximo exponente, dijimos, es Hume. El razonamiento de este filósofo escocés es in nuce sumamente simple, y en ello radica su fuerza. En efecto, de la experiencia no puede obtenerse el concepto de obligación o exigencia moral que, aunque análoga a otro tipo de exigencias, como las físicas o naturales, que más tarde serán equiparadas por Kant al asunto del imperativo categórico, no parece encontrarse en el mundo a través de los sentidos. En otras palabras, la exigencia moral no se encuentra en la experiencia sensible como sí puede hallarse la exi-

\footnotetext{
${ }^{3}$ De todas formas, es posible todavía distinguir entre principium essendi, principium cognoscendi y essentia obligationis, de suerte que la esencia de la moralidad se concentraría en esta última, Cf. Rosmini, Antonio, Storia comparativa e critica dei sistemi intorno al principio della morale, Cap. VII, a. 2. De todas maneras, nosotros en este trabajo no haremos la triple, sino la doble distinción, de suerte que en el principium essendi implicamos la essentia obligationis.

${ }^{4}$ Las denominaciones son varias y tienen sus distintos matices, como sucede con la "ética cordial" (Cortina), "ética del corazón" (D. Von Hildebrand) o "razón del corazón" (De Monticelli).
} 
gencia natural, por ejemplo que los cuerpos caigan al suelo (aun en Hume encontramos problematizada esta misma exigencia). Los hechos, para Hume, son como son y nada se puede obtener de ellos, por consiguiente, tampoco puede extraerse la exigencia moral de ellos mismos. Si se obtiene o extrae una exigencia moral a partir de los hechos, se cae en lo que los continuadores de esta escuela Ilaman "falacia naturalista". Los sistemas morales que dan el paso del ser al deber-ser cometen semejante falacia, de acuerdo con la visión emotivista, ya que, como afirma Hume, no hay causalidad, sino que se trata de una costumbre, de tal suerte que no hay forma de deducir el deber-ser del ser. A lo sumo, queda un sentimiento de aprobación o desaprobación, como sostiene este autor en su $A$ Treatise of Human Nature.

Ciertamente que, como otros autores han sostenido ya, la supuesta falacia naturalista de Hume no puede ser más que falaz en sí misma. La razón también es simple: no se encuentra título suficiente alguno para asegurar que no hay por qué no extraer la exigencia moral a partir de los hechos. Nosotros preferimos hablar, en el caso de la filosofía moral, en vez de "hechos", de objetos, pues la primera denominación puede implicar equívocos desde el punto de vista gnoseológico. En este sentido, consideramos que es del todo legítimo obtener algunos deberes a partir de ciertos objetos, los cuales, en sí mismos, primero, o bien por convención, en segundo lugar, poseen ciertas cualidades o características que exigen, frente a un agente moral, cierto respeto, de donde surgen sus derechos y consecuentes deberes para el agente moral. En otros términos, estos deberes hacia los objetos dan origen a los derechos que éstos tienen, de igual suerte que estos deberes, constituidos también como derechos, generan que el agente moral deba cumplirlos o respetarlos ya que, de lo contrario, violaría o denigraría de alguna manera al objeto ${ }^{5}$. En consecuencia, es a partir de los objetos que encontramos los deberes o exigencias morales. Así sucede que, en el caso de captar o percibir un objeto que resulta ser un hombre, distinguimos en él ciertas características que lo hacen digno de ser sujeto de determinados derechos por el hecho de ser tal; estos derechos, a su vez, engendran el

\footnotetext{
${ }^{5}$ En la ética fenomenológica es posible hallar autores que se acercan a esta postura, que es más rosminiana que fenomenológica. El texto central de Rosmini, de donde se desprende esta idea, es Principios de la ciencia moral (traducción de J. Buganza), México, Universidad Veracruzana y Plaza y Valdés, 2010, $175 \mathrm{pp}$. Sin embargo, en la fenomenología es posible encontrar también esta tesis, por ejemplo, como respuesta adecuada al valor, Cf. Hildebrand, Dietrich von, Ética (traducción J. J. García Norro), Madrid, Encuentro, 1983, p. 232.
} 
deber de respetarlos en el agente moral, que ha de limitarse a reconocerlos y a actuar en consecuencia. Pero que no se confunda esta afirmación: es el deber de respetar al objeto el origen del derecho, y este último tiene su sede en el objeto.

Ahora bien, el emotivismo nos resulta yerra en la premisa que lleva a la conclusión de que sólo quedan determinados sentimientos de aprobación o desaprobación hacia ciertos actos y, por tanto, en relación con tales objetos o "hechos". Entonces, si la premisa es errada, puede ser que la conclusión también lo sea. Sin embargo, nos parece, no es así, porque dichos sentimientos o afectos hacia el objeto sí constituyen buena parte del mundo moral del agente. Empero, y he aquí la distinción que buscamos subrayar, el sentimiento va acompañado de algo más, que es el conocimiento del objeto. Sin objeto, no hay ni conocimiento ni tampoco emoción o afección. El conocimiento y la emoción (o afección) son intencionales, esto es, se refieren al objeto. En otros términos, el conocimiento y la emoción acaecen en el sujeto, pero se refieren siempre a un objeto; y este objeto es, como su nombre mismo lo señala, objetivo y, en cierto modo, independiente del sujeto. Es el sujeto el que lo constituye en objeto, pero el conocimiento y la afección del sujeto se refieren sin duda a un objeto, a algo que no es el sujeto mismo, sino a algo que lo trasciende o está más allá de él. El error del emotivismo, a nuestro parecer, reside en elevar a principum essendi de la moral a la emoción, en vez de visualizarla como un principium cognoscendi. No es la emoción la que constituye la moralidad de algo, sino un efecto, eso sí, importante, para conocer la moralidad. Éste es el matiz que buscamos distinguir frente al emotivismo, que en siglo $X X$ ha tenido importantes cultivadores, y que deja sentir su influencia también en la filosofía del siglo XXI.

En efecto, parece que el emotivismo se acepta hoy en día como la doctrina práctica a seguir. Atrás han quedado los tiempos en los cuales seguir la razón y sujetar las propias pasiones era el ideal a imitar. La razón, desprestigiada ya en la filosofía contemporánea por ser incapaz, dicen, de dirigir la actividad del hombre, y de ser culpable de las grandes catástrofes humanas y ambientales que enfrenta la humanidad desde finales del siglo XIX, pretende ser dejada de lado y sustituida por algo más inmediato. Consecuentemente, esta razón, entendida en su vertiente instrumental, ya ha sido criticada por la filosofía, y hasta equiparada con la "metafísica" por ser su más alto culmen, como se muestra 
en la filosofía de Hegel. Así, es frecuente escuchar que la metafísica es culpable de tan terribles crímenes, cuando en realidad la metafísica como tal no existe. Pero dicha crítica a la razón ha buscado su sustitución por algo adyacente. ¿Qué de más inmediato queda que no sean las propias sensaciones? Mismamente, la sensación y su consecuente emoción son elevadas en la cultura contemporánea a los lugares que antes ocupaba la sola razón, la razón que no se afecciona, sino que se muestra siempre fría y rígida, inflexible y dominante.

Como ha dicho Michel Lacroix, se ha pasado de un homo sapiens a un homo sentiens. Tanto desde el punto de vista de la política, en donde las "emociones políticas" toman un puesto privilegiado, pasando por los medios de comunicación o mass media que indican lo que los usuarios han de sentir con cada noticia, con cada acontecimiento, hasta el ecologismo con estados emotivos de pertenencia (New Age) y la música que es utilizada como liberación de las emociones. Como bien afirma Giacomo Samek Lodovici, "Muy a menudo el hombre contemporáneo va en busca de vibraciones emotivas, busca alimentar las continuas y siempre más intensas emociones, su valor-fin consiste en estar emocionado", de igual suerte que sentio ergo sum, o sea, "ser significa sentir", implicando el imperativo de "libera tus emociones", que se vuelve la norma a seguir ${ }^{6}$. Pero, en verdad, ¿es posible y hasta deseable que el comportamiento humano, y más todavía las acciones éticas, sean guiadas por la sola emoción? ¿No nos lleva una postura de tal cuño a los callejones del relativismo que, en términos morales y legales, resulta sumamente peligroso para la convivencia humana? Finalmente, ¿el hombre puede perfeccionarse como hombre siguiendo sus emociones?

Curiosamente, ha sido la fenomenología la que ha venido a renovar la valoración sobre la experiencia en el ámbito filosófico, no circunscribiéndola a la recepción sensible, es decir, a la sola sensación, que es a lo que llevaron, en el ámbito de la filosofía inglesa, el empirismo y su consecuente sensismo. En este sentido, la filosofía continental ha apostado, aunque no lo demostraremos, por una visión amplia de la experiencia, en contraposición a una más estrecha que podría denominarse, por razones sintéticas, anglosajona. No obstante, y como hemos visto, el asunto de los sentimientos en el campo moral no ha estado fue-

\footnotetext{
${ }^{6}$ Para la inspiración de este párrafo, Cf. Samek Lodovici, Giacomo, "Considerazioni teoretiche preliminari ad una paideia della virtù", en Rivista di Scienze dell'Educazione, XLIX/3, 2011, p. 374.
} 
ra del ámbito anglosajón, pero ha sido la fenomenología (la filosofía continental), la que más fructíferamente la ha trabajado.

\section{EL PAPEL DEL CORAZÓN EN LA ÉTICA A PARTIR DE LA FENOMENOLOGÍA}

Creemos del todo cierto que las emociones o afectos, que tradicionalmente se ha englobado como "el papel del corazón" en la ética, juegan un rol de primera línea en dicho ámbito. Pero hay que tomar estas afirmaciones con cautela, debido a que pueden incluir ciertas confusiones. En efecto, el agente moral, una vez que capta un ente, cualquiera que éste sea, capta lo que es; sobre este conocimiento, y respetando el principio evidentísimo de la sindéresis, ha de reconocer el ser que posee tal ente, que es en lo cual consiste la exigencia moral, es decir, la exigencia que tiene el ente u objeto frente al sujeto o aquel que conoce. El conocimiento directo, que es la manera sintética de llamar al primer acto, es el fundamento ontológico para hablar del segundo acto, que es el reconocimiento del ser del ente en cuestión; este segundo acto es ya un acto voluntario, o reflexión voluntaria, ya que se vuelve libremente sobre lo conocido. En este punto, el hombre, como agente libre, es capaz de seguir o no voluntariamente el conocimiento directo, que se constituye, así, en norma próxima del juicio moral o estima práctica, con lo cual se obtiene un deleite o dolor intelectual, pues a partir del reconocimiento se sigue un vivo placer o un vivo dolor, dependiendo de si la aprehensión ha sido sobre el bien o sobre el mal. El juicio moral tiene aparejado, entonces, un amor u odio prácticos, que dan origen, por último, al acto externo, que es el que comúnmente calificamos de moral, por ser público; sin embargo, y como vemos, el origen del acto moral no está en el acto externo, sino que este último es la conclusión de un acto que se origina con la reflexión (voluntaria), ya que es ahí donde el hombre es capaz de seguir o no el conocimiento directo. En este esquema que hemos reproducido también se aprecia el lugar o papel que desempeña el sentimiento o corazón en la ética, el cual es, como vemos, secundario con respecto al juicio o estima práctica, pero primario desde el punto de vista de su efectividad en relación con el acto externo. Con estas anotaciones, revisemos, primero, qué afirma sobre este asunto Mario Boies; luego, veremos qué dice sobre este mismo tema Roberta De Monticelli en su libro L'ordine del cuore, recientemente vuelto a editar. De 
esta manera, el lector podrá tener cierta claridad en la postura que sostenemos.

Cierta tradición filosófica, que vemos expuesta en el pensamiento de Mario Boies, relacionada especialmente con la fenomenología de los afectos, pareciera pretender la autonomía de las emociones morales, cuando en realidad esos "afectos morales", como resulta conveniente denominarlos, pueden reducirse al menos parcialmente al conocimiento y a la voluntariedad, por lo que uno y otro son igualmente intencionales, es decir, se refieren a un objeto, a algo distinto, pues, del sujeto. El apetito, como nos parece mejor denominar a esta "esfera" que pretende autonomía en Boies, puede ser algo que recibe el paciente (el agente moral, en este caso, recibe cierto afecto o es afectado por el objeto), o bien tiende activamente hacia un objeto. Pero en ambos casos, el sujeto es el mismo y el objeto también. Por tanto, puede decirse que el sujeto es afectado por un objeto y, por ello, tiende hacia él. Esta afectación de la que hablamos puede ser entendida en términos de motivación. En un laudable artículo, Boies explica lo siguiente:

Una de las mayores aportaciones de la PC [psicología cognitiva] post-kohlbergiana a la TMP [teología moral post-conciliar] es haber contribuido a entender mejor la influencia del factor afectivo en el juicio moral y en la toma de decisión ética. En efecto, la TMP considera que la afectividad es preponderante en la conducta humana y no puede ser disociada del comportamiento moral responsable. Los sentimientos y las emociones impregnan los actos del sujeto moral, la sensibilidad moral, el temperamento, la personalidad moral (o ethos-carácter), etc. De esta manera, una decisión moral no es solamente un proceso racional, sino también emotivo. Desde esta perspectiva es posible afirmar que las emociones pueden instruir a la razón e, inversamente, que la razón puede instruir las emociones. Al insistir sobre la preponderancia de la esfera afectiva y emotiva en el juicio moral y la toma de decisión ética, la TMP preconiza la armonía entre la razón y la afectividad. ${ }^{7}$

Examinemos las siguientes afirmaciones: ( $i$ ) asegura que la afectividad es "preponderante" en el juicio moral (y por consiguiente, a nuestro juicio, en relación con la decisión ética, el juicio equivale en cierto modo a la decisión tomada). Pero el término preponderante tiene una connotación que consideramos

\footnotetext{
${ }^{7}$ Boies, Mario, "Hacia una comprensión psico-teológico-moral del juicio moral", en Moralia. Revista de ciencias morales, XXXI/117, 2008, p. 43.
} 
incorrecta, ya que quiere decir "superioridad"; si es así, este autor estaría afirmando que la afectividad es aquella instancia definitiva que gobierna el juicio moral, y esto es precisamente lo que creemos debe revisarse. Si el juicio moral es consecuencia de la afectividad, y la afectividad es algo que acaece en el sujeto sin que en ella medie el uso libre de la razón, no se aprecia cómo es que puede llamarse a semejante juicio moral "decisión", porque en realidad no se ha decidido, debido que para decidir es necesario que haya libertad en el agente; mas la afectividad por sí misma no es un acto libre; luego, el juicio moral tampoco. Esto impacta en la afirmación sucesiva: (ii) la afectividad no puede ser disociada del comportamiento moral responsable. Ciertamente, la afectividad está presente en el comportamiento moral responsable, y en esto tiene toda razón Boies. Empero, una cosa es que la afectividad esté presente en el comportamiento moral responsable y otra que sea la instancia "preponderante"; la afectividad no puede llamarse libre en sí misma si no está precedida por el juicio moral. Tiene razón Boies al decir (iii) que la decisión moral no es sólo un proceso racional, sino también emotivo. Sin embargo, no nos parece del todo claro la siguiente parte de su afirmación: (iv) las emociones pueden instruir a la razón e, inversamente, que la razón puede instruir las emociones; pero, en el caso del juicio moral, ¿cómo es que la razón puede ser instruida por las emociones? Opinamos que, únicamente, es aceptable esta tesis si se entendiera que las emociones son un principium cognoscendi, pero nunca un principium essendi, de igual suerte que ante el asesinato de un ser humano, del todo injustificado, sin más por sentir o tener el afecto o la emoción del desagrado o repugnancia ante semejante acto, se siga que el acto es malo. Tal sentimiento, afecto o emoción es sólo principium cognoscendi; si alguno no sintiera repugnancia por dicho acto, no por ello el acto deja de ser malo, sino simplemente no es capaz de conocer la maldad del acto a partir del sentimiento. En consecuencia, no vemos cómo infiere Boies $(v)$ que la preponderancia de la esfera afectiva y emotiva en el juicio moral y la toma de decisión ética permita a la teología moral post-conciliar preconizar la armonía entre la razón y la afectividad; por el contrario, parecerían hasta encontrarse una frente a la otra sin armonía.

La tesis de Boies nos resulta, en el fondo, correcta, pero invirtiendo los términos, o sea, afirmando la preponderancia del juicio práctico de la razón sobre el afecto, ya que este último da lugar a equívocos. Creemos que puede haber armonía entre la esfera racional y la afectiva siempre y cuando la esfera 
afectiva se refiera a los afectos racionales y no a los afectos animales, que sólo por participación podrían ser racionales. En consecuencia, si es verdad que el juicio moral es la conclusión de la deliberación en orden a la praxis, nos resulta igualmente cierto que en este juicio está implicada la afectividad o cor, que es la dimensión afectiva del hombre, que estimamos intermedia entre el conocimiento y la voluntad, aunque no una facultad autónoma.

Y es que el juicio práctico no es otra cosa que una estimación sobre el objeto. La estimación sobre el objeto no es otra cosa, a su vez, que un juicio con el cual se expresa el amor hacia un objeto. Pero este juicio o estimación es libre; de lo contrario, no habría forma de exigir responsabilidad moral por los actos que siguen a este juicio o estimación. En consecuencia, habría que sostener que hay libertad en los afectos (en el amor hacia el objeto), y sólo así nos parece que puede llamarse autónoma, en cuanto que es el sujeto quien decide si ama más o menos a un objeto cualquiera. Cuando un objeto es presentado intelectualmente al sujeto, este último es capaz de afeccionarse por el primero. Si se ejercita una afección correspondiente o adecuada al objeto, puede hablarse de una afección racional; si se ejercita una afección inadecuada al objeto, entonces se trata más bien de una afección irracional, pues seguir a la razón en este caso equivale a una afección racional. Sólo así, a nuestro juicio, el juicio moral implica a los afectos. Si no es así, se trata de afectos sin más, los cuales no pueden ser imputados moralmente $y$, por tanto, no exigen responsabilidad (moral).

No negamos, entonces, el papel de la afectividad, que incluso ya desde la fenomenología puede rastrarse, porque al describir un objeto, aunque éste sea distinto del sujeto, no dejan de estar unidos, al menos intencionalmente, y esta unión, además de cognoscitiva, es afectiva. Pero esta afectividad se explica, en el campo del contexto moral, a partir de lo que tradicionalmente se denomina voluntad, que es la facultad humana para afeccionarse con el bien en universal, el cual está estrechamente vinculado con el ser en universal que intuye el entendimiento. El entendimiento, al estar conformado por la intuición del ser en universal, presta el objeto afectivo a la voluntad, la cual justamente se afecciona con este ser al que ve desde la perspectiva del bien. La voluntad es, en este sentido, el amor habitual o actual hacia el ser, por lo cual se sigue que si el entendimiento posee sus leyes objetivas en torno al ser, éstas traspasan también a la voluntad, debido a que la voluntad es, por decirlo así, el despliegue afecti- 
vo del mismo entendimiento, la misma inteligencia capaz de afeccionarse por el objeto $^{8}$. Si esto es así, y si el hombre es capaz de conocer objetivamente, entonces es capaz de afeccionarse de la misma manera. Por lo cual no hay por qué aceptar que los afectos, los afectos que llamamos racionales, que son los que se desenvuelven en este ámbito propiamente humano, tengan que ser incognoscibles. Por el contrario, son susceptibles de ser explicados, o sea, es posible dar razones de ellos, pues se basan en el juicio práctico de la razón práctica que puede entenderse en la tesitura de una explicitación del amor que se tiene por el objeto.

El bien moral no está separado de las emociones, pero se trata de una emoción espiritual a la cual llamamos, en general, amor. Y es que el bien moral implica que la cosa amada se ame de acuerdo con lo que ella es, es decir, objetivamente, y no de acuerdo con mis propias preferencias o mis deseos; el bien moral se deriva de amar a la cosa tal como es en sí misma, sin inmiscuir mi propia utilidad en la valoración o juicio que hago sobre ella. El juicio o valoración no es otra cosa que la expresión que se efectúa en torno al amor que se tiene por el objeto, el cual puede ser objetivo y, en consecuencia, bueno moralmente; o bien subjetivo y, por lo general, aunque no siempre, malo moralmente en cuanto a las acciones externas que el hombre lleva a cabo sobre ella, que son precisamente las acciones susceptibles, en el mundo público, de ser evaluadas moralmente. Empero, estas acciones externas tienen su fundamento o raíz en la valoración libre que se efectúa sobre los objetos, en el amor libre que se les confiere, y este amor estará conforme al objeto si se ajusta a él, si lo ama de acuerdo con lo que es; y será disconforme si no lo ama de acuerdo con lo que es, sino sólo por la sola y propia utilidad.

Es cierto que sobre el tema del objeto el debate ha estado y sigue estando abierto. Mas la fenomenología, que en buena parte creemos que recupera tesis clásicas, afirma que "el objeto se da o brinda a través del fenómeno, que es lo que nos aparece a la conciencia, de manera que 'silla' y 'persona' tienen dos modos muy diversos de aparecer y darse a conocer. A estos modos corresponden también dos diversos estilos de trascendencia, dos diversos modos de

\footnotetext{
${ }^{8}$ Cf. Buganza, Jacob, El ser y el bien, Stresa, Edizioni Rosminiane Sodalitas, 2010, p. 116; y Buganza, Jacob, Nomología y eudemonología, Stresa, Edizioni Rosminiane Sodalitas, 2013, 302 pp.
} 
ser" $^{\prime \prime}$. En efecto, la fenomenología ha rescatado lo que la tradición ya había denominado "conocimiento directo" o "experiencia inmediata", que no se limita únicamente a la intuición o conocimiento sensorial, sino que la experiencia es mucho más amplia, de modo que abarca tanto a la experiencia intelectual como a la emotivo-volitiva. El sentir, para De Monticelli, pertenece también a esta especie de conocimiento directo, de manera que, para ella, una buena parte de las cualidades que pertenecen a las cosas se da a través del acto de "sentir". Examinemos su interesante tesis:

El sentir es esencialmente percepción de cualidades de valor, positivas o negativas, de las cosas. Podemos Ilamarla la primera tesis fenomenológica sobre la vida afectiva. El sentir es el modo de presencia o dadidad (datità) de las más variables cualidades axiológicas o de valor. Esta apertura a las cualidades axiológicas es la intencionalidad (o sea, el tipo de relación con la realidad) característica de todas las experiencias de la esfera afectiva.

Para el fenomenólogo, el sentir es, por tanto, una modalidad de nuestra experiencia de lo real, y para nada un reino de la arbitrariedad subjetiva, y mucho menos un mero sistema de alarmas o incentivos funcionales para la supervivencia del organismo.

[...] También aquí como en el dominio sensorial, la reflexión puede ayudar a corregir una percepción errónea; pero es una nueva percepción que confirmará provisionalmente la corrección. [...] El sentir constituye el modo de evidencia o de "llenado intuitivo" característico de ciertos juicios (los juicios de valor), así como la percepción sensorial es el modo de evidencia de otros juicios. ${ }^{10}$

Esta autora estima que la percepción del valor se encuentra en el sentir. He aquí el punto que requiere mayores precisiones, pues si en el sentir se dan las esencias axiológicas de manera inmediata, habrá que ver qué se entiende por sentir. Si sentir quiere decir el acto a través del cual se nos brinda un ente cualquiera, es decir, si se refiere al acto con el cual un sujeto entra en contacto inmediatamente con un objeto, entonces nos parece certera su tesis, porque es en el momento en que el objeto se da o brinda al sujeto cuando este último es capaz de apreciar las cualidades (valores) que posee el primero. Pero si el sentir implica algo ajeno a la razón, o sea, si el sentir es meramente algo irracional

\footnotetext{
${ }^{9}$ De Monticelli, Roberta, L'ordine del cuore. Etica e teoria del sentire, Milano, Garzanti, 2012, p. 41.

${ }^{10}$ Ibíd., pp. 71 y 72 (subrayados del original).
} 
o algo que acaece sólo en el plano sensitivo, no podemos aceptar la tesis de De Monticelli. En otros términos, si el sentir es la mera experimentación sensible sin que en tal acto entre la razón, entonces no habría manera de caer en la cuenta de que lo que se "siente" sea algo perteneciente o no al objeto. Este acto de sentir, por el cual el objeto y el sujeto entran en relación, implica a la inteligencia; y es que la inteligencia puede asimismo sentir, que es lo que nosotros estimamos sucede justamente en el ámbito axiológico. La inteligencia, al tener la presencia de un objeto inteligible, lo siente, en cuanto éste está presente a ella, pues el sentir hace referencia a algo singular, en este caso a un objeto. Creemos que De Monticelli concuerda con esta tesis, porque ella de inmediato habla de la "intencionalidad" de las cualidades axiológicas, y esta intencionalidad tradicionalmente se asocia a un objeto: la cualidad que se percibe en el objeto pertenece realmente a éste.

Consideramos que De Monticelli se acerca a lo que exponíamos en líneas anteriores cuando afirma que el sentir no es un reino de la "arbitrariedad subjetiva", y mucho menos es un "sistema de alarmas" o "incentivos funcionales" que la evolución nos ha colocado. Sin embargo, no queda claro del todo su posición en torno a este "sistema de alarmas", porque bien puede ser que éste sea objetivo, pues se refiere precisamente a un objeto de la realidad, de modo que un animal, o incluso el hombre mismo, poseen este "sistema" para escapar o para acercarse de manera instintiva a los objetos que tienen ciertas cualidades dañinas o benéficas; lo que ya no podría ser este "sistema de alarmas" sería una cuestión moral, pues para que el ámbito moral se dé, es forzoso que el acto con el cual tiene su origen algo que es cualificado dentro de tal ámbito sea un acto libre. El sentir no es un reino de la arbitrariedad subjetiva en cuanto el valor que posee el objeto permanece incólume y no está sujeto al capricho del sujeto; lo que es arbitrario es el reconocimiento que se le brinda a tal valor objetivo, lo cual es ya un asunto precisamente subjetivo, ya que es voluntario.

En este sentido, opinamos que el sentir es un modo de "evidencia" para los juicios de valor, pues es en el contacto directo con el objeto que éste revela al sujeto sus características y, basadas en ellas, sus valores. Ahora bien, aun con todo nos parece un equívoco hablar del juicio moral y la afección o sentimiento (el "sentir" del que habla De Monticelli) sin distinguir entre uno y otro. Porque a veces da la impresión de que, para evitar el "racionalismo", se quiere recurrir al "sentir" como si fuera equivalente a juicio, lo cual eventualmente podría llevar 
al emotivismo, que es equívoco. Es cierto, primero, que el "sentir" puede equivaler al juicio, pero en sentido muy lato. Puede decirse que cuando un sujeto efectúa un juicio sobre el valor de un objeto, se habla de manera impropia de "sentimiento"; sin embargo, es posible decir que el juicio de valor efectuado equivale al sentimiento que tiene el sujeto por el valor que posee el objeto. Pero es sólo una manera aproximativa de aferrar el problema, aunque es verdad que el sentimiento hacia el objeto implica de una $u$ otra forma al juicio que se efectúa sobre él, pues el juicio efectuado implica de una u otra manera el sentimiento que guarda el sujeto hacia el objeto. Nos parece mejor, y hasta conveniente, distinguir entre el juicio y el sentimiento o afección o sentimiento que se tiene hacia el valor del objeto. Porque, por otra parte, también resulta del todo posible sostener que los sentimientos no pueden ser justos o injustos sino a condición de que sean precedidos por un juicio de valor sobre el objeto; y estos sentimientos, o este sentir, como a veces se le llama, no es justo o injusto sino en la medida en que hay un juicio práctico que lo precede; juicio que podemos cualificar, moralmente, como libre y, en consecuencia, como bueno o malo. Sólo así aconsejamos que es propio hablar de la "justicia del sentir" (giustezza del sentire), debido a que el sentir no puede ser justo o injusto per se, sino que es justo o injusto el juicio previo que da la pauta para un sentir racional o recto.

Esta concepción entre el juicio moral y el afecto nos ayuda a escapar del relativismo, que también Roberta de Monticelli aprecia como un problema central de la ética contemporánea. Ella visualiza el problema en relación con las normas morales, las cuales tienen un fundamento en la diversidad de maneras en que pueden jerarquizarse los valores. En este sentido, se daría un "relativismo moral si se sostuviese que ninguna de las normas está mejor fundada que la otra, o fundada sobre el orden justo. He aquí por qué es absolutamente indispensable que una teoría de la conciencia moral indique dónde buscar la evidencia para dirimir casos como éstos -aunque no necesariamente quiera dirimirlos ella misma: no es esto, en definitiva, su objetivo" ${ }^{11}$. En efecto, el apelo a estas evidencias parece ser el punto de partida para zanjar parte de los problemas en los que se inmiscuye el relativismo, siempre volcado a cuestiones de carácter particular o circunscrito. Mas, en última instancia, la ética se juega o dirime en

${ }^{11}$ Ibíd., p. 117 (subrayados del original). 
relación con los objetos hacia los cuales se ejercitan los deberes morales, que poseen ciertas exigencias. Empero, no deja de haber resquicios de relativismo una vez que se busca aplicar la ley moral a los casos muy concretos y específicos. Aquí entra en juego la lógica moral, que se sirve de la conciencia moral, y la retórica que da forma a esta lógica, no siempre matemática, sino un tanto movediza y persuasiva. Expliquemos más nuestra tesis.

La ética se refiere primariamente a la esencia de la obligación moral, que tiene su sede en la exigencia moral de los entes en relación con el agente moral o libre. En este sentido, la ética no deja de ser formal, aunque tiene también cierta materialidad, la cual se expresa en los objetos que poseen precisamente lo que llamamos exigencia moral. Pero el elemento formal, que pretende el carácter absoluto, está esencialmente presente en la ética, y muchas veces en la filosofía contemporánea esto ha sido olvidado. Ahora bien, la aplicación de las normas universales, esto es, formales, a los casos concretos, no es ya una cuestión de ética general, sino de lógica moral, la cual labora con la noción de conciencia moral, ya que es la facultad de la cual se sirve el hombre para aplicar las fórmulas morales a las acciones, advirtiendo (por ello es conciencia) el acto moral que se efectúa. Sin embargo, nos parece que la lógica moral no es del todo apodíctica, sino que posee cierta retórica, lo cual equivale a la conciencia de que, al tratarse de asuntos humanos en los que la ley general busca aplicarse a los casos particulares, entra en juego cierta relatividad (y hermenéutica, en cuanto se interpreta la ley general o universal en los casos concretos) para aterrizar, por decirlo así, aquélla en éstos, mas no corresponde a carencia de objetividad ${ }^{12}$.

Gracias a la conciencia moral, nos percatamos de la serie de inferencias, no siempre apodícticas, que efectuamos para aplicar las leyes o normas morales generales a los casos particulares. ¿Cuál es el papel del corazón en este contexto? Nos parece que queda claro: en la serie de inferencias, en algunos argumentos está presente el sentimiento (moral, como veremos); de aquí que el razonamiento moral, aunque lógico, no sea apodíctico o matemático en todo momento, pero sí implica lo que hemos llamado "afectos racionales". Por eso es que el razonamiento moral está atento a la circunstancia, al momento, al sen-

\footnotetext{
${ }^{12}$ Cf. Buganza, Jacob, "El carácter retórico de la ética a partir de Aristóteles", en Devenires, XII/24, Universidad Michoacana de San Nicolás de Hidalgo (2011), pp. 128-148; Cf. Beuchot, Mauricio, Filosofía del derecho, hermenéutica y analogía, Santafé de Bogotá, Universidad Santo Tomás, 2006, 190 pp.
} 
timiento que puede despertar en el agente cierto argumento. $Y$ de ahí que la retórica, una retórica moral, como lo es la aristotélica, ayude tanto desde el punto de vista de su manejo como a partir de la comprensión; desde el punto de vista del manejo, la razón es que la retórica de Aristóteles no está despojada de la moralidad, como sí lo están otros modelos retóricos; desde de la comprensión, el modelo aristotélico nos ayuda a entender el proceso subjetivo que se efectúa en el agente al momento de tomar una decisión moral. Entendido así el papel del corazón o sentimiento, veamos lo que al respecto dice Jesús Conill en su Ética hermenéutica: "El sentimiento moral es la capacidad sensible, física, de recibir el impulso racional y transformarlo en motivo" ${ }^{13}$. Efectivamente, esta sentencia del profesor español nos resulta del todo certera, porque el sentimiento moral, que es importante, como hemos visto, para comprender el mundo moral, no se instaura como principium essendi, sino justamente como principium cognoscendi, dado que es la capacidad, nos dice él, física, de recibir el impulso racional, que no es otro que el juicio que efectúa la razón prácticomoral en orden al bien de tal naturaleza, el cual no nos sume en la irracionalidad, pero sí nos permite comprender por qué el hombre alcanza ciertas conclusiones morales.

Aunque las conclusiones a las cuales se llegan a través del razonamiento moral pueden ser consideradas relativas, no implica necesariamente un relativismo extremo, ni mucho menos, porque la misma realidad, es decir, el ente, posee exigencias objetivas que el agente moral debe "reconocer" y "respetar". Además, desde el punto de vista formal, la ética no es necesariamente relativa, sino precisamente absoluta y objetiva, como nos lo hace ver en los tiempos contemporáneos la fenomenología de Roberta De Monticelli. En este sentido, opinamos, hay que leer lo que esta filósofa nos dice acerca de una ética objetiva hodierna que, por un lado, "mantiene las normas obligantes precisamente en virtud de los valores que las fundan, y correspondientes a las exigencias que la realidad precisamente en cuanto cargada de cualidades de valor pone: valores $y$ exigencias que son parcialmente, o sea, inadecuadamente, pero progresivamente, cognoscibles. Una ética que se confiesa, por tanto, lo hemos visto,

${ }^{13}$ Conill, Jesús, Ética hermenéutica, Madrid, Tecnos, 2006, p. 48. 
incluso en este campo, persuadida de que se da una realidad y es respetuosa de sus exigencias. Y esto sería su primer principio"14.

Siendo así, es claro que lo que desde Pascal, y antes de él en San Agustín, y posteriormente en la filosofía de Max Scheler, hemos conocido como l'ordre du coeur, no es necesariamente una tesis que se abra al relativismo extremo ${ }^{15}$. El orden del corazón es el orden en cual, desde el punto de vista moral, deben amarse y respetarse los entes. En otros términos, desde el punto de la vista de la moralidad, el corazón ha de amar al ente por aquello que éste es, y por ello se habla de un ordre, de una congruencia no sólo personal (congruencia consigo mismo), sino una congruencia hacia las cosas mismas, porque el orden moral no es otra cosa que la proporción que debe tener la justa apreciación de los entes, la cual sirve de base para las acciones humanas ${ }^{16}$. Este orden del corazón, este orden de los afectos o de los sentimientos hacia las cosas, hacia los entes, es expresión del bien moral. Desde el punto de vista moral, entonces, y teniendo presente la esfera afectiva o emocional relacionada con dicho punto de vista, nos parece que el sentimiento moral que está a la base del "reconocimiento" del ser de los entes, no es otro que el "respeto", como dijimos en el párrafo anterior. En efecto, el reconocimiento y el respeto van de la mano; el reconocimiento del ser de los entes expresa justamente la esencia de la obligación moral o su principium essendi, mientras que, desde el punto de vista del sentimiento moral, dicho reconocimiento exige que el hombre sienta respeto por el ser del ente, lo cual se expresa en el reconocimiento. El respeto es equivalente a la deferencia hacia el ente en cuanto tal, de manera que, como implica en su definición, la deferencia es la adhesión hacia lo otro, hacia el objeto; y desde el punto de vista moral, la exigencia que posee el ente pide su reconocimiento de parte del agente moral, el cual se afecciona racionalmente precisamente respetándolo.

\footnotetext{
${ }^{14}$ De Monticelli, Roberta, Op. Cit., p. 207 (subrayados del original).

${ }^{15}$ Hemos examinado este asunto, desde el punto de vista rosminiano, en Buganza, Jacob, "Relectura rosminiana de la axiología pura de Max Scheler", en Rivista rosminiana di filosofia e di cultura, CVI/1, 2012, pp. 13-41. Creemos que Scheler, en buena medida, sigue las hormas de San Agustín y Pascal, como se revela en su Der formalismus in der Ethik und die materiale Wertethik. Nos parece que en nuestro artículo se encuentran suficientes claves para visualizar la ética fenomenológica de Scheler a la luz de la de Rosmini.

${ }^{16}$ Rosmini, Antonio, Compendio di etica, n. 106.
} 


\section{CONCLUSIÓN}

Consideramos que puede darse un equilibrio entre el juicio moral, que tiene ciertamente implicaciones intelectuales, y el sentimiento, que implica una esfera esencial para comprender el fenómeno moral. Empero, desde el punto de vista formal, el principio que rige el ámbito moral, porque expresa la esencia de la obligación de tal cuño, es el reconocimiento del ser de los entes. Desde el punto de vista del sentimiento, este reconocimiento exige que el ente sea respetado en sí mismo, esto es, objetivamente, en lo cual vemos cómo se implican la parte intelectiva y afectiva en la moralidad. Si el acento pasa más bien a la parte afectiva, e incluso se hace caso omiso de la intelectiva, entonces el emotivismo se acerca y propone, en última instancia, la irracionalidad de los afectos morales; irracionalidad que, como el mismo nombre indica, pide la separación entre la razón y el mundo afectivo. Sin embargo, desde nuestra perspectiva, parte de la vida afectiva del hombre se vincula a la razón, por lo cual puede hablarse de "afectos racionales", es decir, emociones que están en conformidad con lo que la razón indica. Se trata de ciertos afectos, ciertamente, y no de todos, ya que los hay que son independientes de la razón, aunque eventualmente puedan sujetarse a ella, como sucede con los afectos animales.

Asimismo, y aunque no hayamos tratado el tema en este trabajo, creemos que las virtudes morales no son otra cosa que expresión o desenvolvimiento del amor libre, que reconoce y respeta a los objetos. Las virtudes, máxime las cardinales, eminentemente morales, son el amor puesto en práctica a través de los actos externos que el hombre lleva a cabo. Pero también la vida afectiva es expresión de las virtudes, si por vida afectiva se entiende la "manifestación" de un sentir que es experiencia, más o menos adecuada, de valores en sus variedades y en sus importancias, de manera que la vida afectiva se entienda como las respuestas personales a la experiencia de los valores ${ }^{17}$. De ahí que el corazón debe amar moralmente al ente, respetando siempre el orden objetivo que éste posee desde el punto de vista moral, que no es más que la justa estima que debe tenerse hacia él. De esta manera, el juicio moral y el sentimiento que viene aparejado a él, debe ser de congruencia y respeto hacia las cosas mismas.

17 De Monticelli, Roberta, Op. Cit., p. 85. 


\section{BIBLIOGRAFÍA}

Beuchot, Mauricio, Filosofía del derecho, hermenéutica y analogía, Santafé de Bogotá, Universidad Santo Tomás, 2006, 190 pp.

Boies, Mario, "Hacia una comprensión psico-teológico-moral del juicio moral", en Moralia. Revista de ciencias morales, XXXI/117 (2008), pp. 39-64.

Buganza, Jacob, El ser y el bien, Stresa, Edizioni Rosminiani Sodalitas, 2010, 116 pp.

Buganza, Jacob, Nomología y eudemonología, Stresa, Edizioni Rosminiane Sodalitas, 2013, $302 \mathrm{pp}$.

Buganza, Jacob, "Relectura rosminiana de la axiología pura de Max Scheler", en Rivista rosminiana di filosofia e di cultura, CVI/1 (2012), pp. 13-41.

Buganza, Jacob, "El carácter retórico de la ética a partir de Aristóteles", en Devenires, XII/24, Universidad Michoacana de San Nicolás de Hidalgo (2011), pp. 128-148.

Charpenel, Eduardo, "Los sentimientos y el deber en la filosofía práctica de Kant", en Open Insight, III/2 (2011), pp. 5-29.

Conill, Jesús, Ética hermenéutica, Madrid, Tecnos, 2006, 288pp.

De Monticelli, Roberta, L'ordine del cuore. Etica e teoria del sentire, Milano, Garzanti, 2012, $311 \mathrm{pp}$.

Hildebrand, Dietrich von, Ética (traducción J. J. García Norro), Madrid, Encuentro, 1983, 462 pp.

Rosmini, Antonio, Compendio di etica (al cuidado de M. Manganelli), Roma, Città Nuova y Centro Internazionale di Studi Rosminiani, 1998, 244 pp.

Rosmini, Antonio, Principios de la ciencia moral (traducción de J. Buganza), México, Universidad Veracruzana y Plaza y Valdés, 2010, 175 pp.

Rosmini, Antonio, Storia comparativa e critica dei sistemi intorno al principio della morale, Milano, Fratelli Bocca, 1941, 412 pp.

Samek Lodovici, Giacomo, "Considerazioni teoretiche preliminari ad una paideia della virtù", en Rivista di Scienze dell'Educazione, XLIX/3 (2011), pp. 372-389. 